\title{
A questão trans no cenário brasileiro
}

\author{
Roberto de Oliveira Preu ${ }^{1}$ \\ Carolina Franco Brito ${ }^{2}$
}

ISSN: 2358-0844

п. 10. v. 1 nav.2018-abr. 2019 р. $95-117$.

RESUMO: O presente artigo possui como objetivo principal reunir dados existentes acerca da realidade da população transexual no Brasil e disponibilizá-los como meio de consulta para futuras produções científicas. Esta pesquisa foi realizada e dividida em três partes. No primeiro momento apresenta-se uma breve cronologia de alguns acontecimentos importantes acerca da transexualidade no cenário brasileiro. No segundo, busca-se desenhar um panorama dessa realidade, a partir de dados e notícias publicados em diferentes meios de comunicação e artigos científicos. Por fim, no terceiro momento, serão feitas algumas considerações finais. Faz-se uso de uma metodologia de análise bibliográfica de artigos sobre o tema referido e levantamento de dados recentes a respeito da transexualidade. Esta pesquisa mostra-se relevante visto que não há materiais de fácil acesso acerca de dados concernentes a pessoas transexuais no Brasil.

PALAVRAS-CHAVE: Transexualidade; Violência; Discriminação; Transfobia; Saúde Pública.

\begin{abstract}
The main objective of this article is to gather existing data about the reality of the transsexual population in Brazil and to make them available as a means of consultation for future scientific productions. This research was carried out and divided into three parts. In the first one will be presents a brief chronology of some important events about transsexuality in the Brazilian scenario. In the second part, is drawn a panorama of this reality, based on data and news published in different media and scientific articles. Finally, in the third moment, some final considerations will be made. The methodology used includes bibliographic analysis of articles on the subject referred and survey of recent data on transsexuality. This research is relevant since there are no easy access materials about data concerning transsexuals in Brazil.
\end{abstract}

Keywords: Transsexuality; Violence; Discrimination; Transphobia; Public Health.

Resumen: El objetivo principal de este artículo es recopilar datos existentes sobre la realidad de la población transexual en Brasil y ponerlos a disposición como medio de consulta para futuras producciones científicas. Esta investigación se llevó a cabo y se dividió en tres partes. En el primer momento se presenta una breve cronología de algunos acontecimientos importantes acerca de la transexualidad en el escenario brasileño. En el segundo, se dibuja un panorama de esa realidad, a partir de datos y noticias publicados en diferentes medios de comunicación y artículos científicos. Por último, en el tercer momento, se harán algunas consideraciones finales. Se hace uso de una metodología de análisis bibliográfico de artículos sobre el tema referido y la encuesta de datos recientes acerca de la transexualidad. Esta investigación es relevante ya que no hay materiales de fácil acceso acerca de datos concernientes a personas transexuales en Brasil.

Palabras clave: Transexualidad; Violencia; Discriminación; Transfobia; Salud Pública.

1 Mestre em Psicologia pela Universidade Federal Fluminense (UFF) e doutor em Psicologia (Psicologia Experimental) pela Universidade de São Paulo (USP). Professor do Departamento de Psicologia UFF - Volta Redonda. E-mail: robbypreu@gmail.com

${ }^{2}$ Graduada em Psicologia UFF - Volta Redonda. E-mail: carolinafrancobrito@ gmail.com 
Um mundo de igualdade não é feito de pessoas iguais, mas de pessoas com direitos iguais para serem diferentes.

Rosana Hermann.

A transexualidade tem se tornado cada vez mais objeto de estudo de diferentes áreas do saber científico que a analisa sob diversos aspectos. Hegemonicamente é definida por um "sentimento intenso de não-pertença ao sexo anatômico, sem por isso manifestar distúrbios delirantes [...], e sem bases orgânicas (como o hermafroditismo ou qualquer outra anomalia endócrina)" (CASTEL, 2001, p. 77). Esse modo de compreensão da transexualidade somente é possível dentro do sistema sexogênero: a linearidade entre esses dois constructos é postulada como natural e como padrão de normalidade, ou seja, espera-se que o gênero - entendido como uma identidade que se forma dentro de uma cultura - seja correspondente ao sexo - supostamente determinado pela natureza. Por não estar em acordo com as expectativas desse contínuo, a transexualidade é apresentada, frequentemente, como um desvio ou até mesmo uma patologia.

Em uma pesquisa realizada anteriormente acerca de alguns desdobramentos da naturalização das noções de sexo e gênero no entendimento social e científico da transexualidade, algumas dificuldades se apresentaram: praticamente não foram encontrados dados oficiais sobre a realidade dessa população no Brasil. A maior parte das informações a que se teve acesso foram a partir de publicações da imprensa e de organizações nacionais e internacionais. Uma questão parece se apresentar frente a isso: é possível afirmar que a inexistência desses dados produzidos pelos órgãos oficiais do Brasil se configura como um modo de transfobia na medida em que a existência dessa parte da população é desconsiderada quando leva-se em conta somente o dito sexo biológico dos sujeitos em seus levantamentos? Visto que não há muitos trabalhos no meio acadêmico que concentrem informações atuais acerca da realidade da população transexual no Brasil, o presente artigo pretende reunir alguns dados existentes em diferentes meios e disponibilizá-los a fim de facilitar futuras consultas e para produção de novos materiais.

O fenômeno transexual no Brasil possui suas particularidades e histórias próprias que precisam ser constantemente colocadas em pauta para compreendermos melhor a dinâmica do país. Em um primeiro momento, serão abordadas questões referentes a essa história, a partir de uma breve cronologia de alguns acontecimentos importantes acerca da transexualidade. Posteriormente, será feita uma apresentação de um panorama da realidade brasileira, a partir de dados e notícias publicados em meios de comunicação e artigos científicos. E, por fim, serão feitas algumas considerações finais.

Periódicus, Salvador, n.10, v. 1, nov.2018-abr.2019 - Revista de estudos indisciplinares em gêneros e sexualidades Publicação periódica vinculada ao Grupo de Pesquisa CUS, da Universidade Federal da Bahia - UFBA ISSN: 2358-0844 - Endereço: http://www.portalseer.ufba.br/index.php/revistaperiodicus 


\section{Breve cronologia da transexualidade no Brasil}

Em 1971, foi realizada, no Brasil, a primeira cirurgia de redesignação sexual pelo cirurgião Dr. Roberto Farina. Essa prática ainda não era regulamentada e reconhecida, o que fez com que Farina se tornasse alvo de dois processos, um deles criminal e outro no Conselho Federal de Medicina (CFM), nos quais foi considerado culpado. Contudo, apesar de ainda serem consideradas ilegais nesse período, diversas cirurgias foram realizadas clandestinamente desde a década de 70 (SAADEH, 2004, p. 45). Iniciaram-se, nessa época, algumas ações isoladas nos âmbitos jurídico e legal no sentido de uma tentativa de obter permissão para a realização de intervenções cirúrgicas e retificação dos documentos oficiais. Em 1979, o deputado José de Castro Coimbra apresentou um projeto de lei de sua própria autoria que visava regulamentar, na área jurídica, as questões referentes às pessoas transexuais. Esse projeto de lei foi aprovado pelo Congresso Nacional, entretanto, o então Presidente da República João Figueiredo, durante a ditadura militar, o vetou (cf. SAADEH, 2004, p. 45).

Nesse mesmo ano, o Conselho Federal de Medicina foi consultado sobre a possibilidade de se colocar próteses mamárias de silicone em uma mulher transexual. O parecer do CFM foi desfavorável e a prática foi considerada desnecessária com base no artigo 92 do Código de Ética Médica, que proibia a "indicação e execução de terapêutica ou intervenção cirúrgica desnecessária ou proibida pela legislação do país. A partir disso, estes pacientes foram indicados para tratamento psiquiátrico ou apoio psicológico" (AMARAL, 2007, p. 48). Esse protocolo passou por novo parecer de consulta em 1980: foi colocada em questão a noção de necessidade de tratamento, visto que este possui um sentido sociopsicológico, além da relevância de perícias para que se compreenda se as pessoas que demandam esse tipo de intervenção realmente possuem algum problema psiquiátrico. Na parte conclusiva, foi sugerido que se criasse uma resolução que regulamentasse as cirurgias de transgenitalização e intervenções secundárias.

Em 1990, outro "Processo de Consulta CPM 0871/90 - PC/CFM/ 12/1991 [...] teve início no CFM em grau de recurso após ter passado por parecer negativo no Conselho Regional de Medicina do Estado de São Paulo" (AMARAL, 2007, p. 48). Nele, o homem transexual, cujo nome apresentado no processo é o do registro de nascimento, Marcia Vinharski da Silva, pediu autorização ao CFM para se submeter à cirurgia de ablação das mamas, indicada na época pelo cirurgião plástico Dr. Evaldo Lugue, a partir de sua consideração de que esta intervenção poderia permitir-lhe uma melhor adaptação na sociedade. Além disso, Silva pediu uma orientação ao Serviço de Assistência Jurídica da Prefeitura de São Bernardo do Campo (SP) sobre como proceder para uma modificação dos seus documentos,

Periódicus, Salvador, n.10, v. 1, nov.2018-abr.2019 - Revista de estudos indisciplinares em gêneros e sexualidades Publicação periódica vinculada ao Grupo de Pesquisa CUS, da Universidade Federal da Bahia - UFBA ISSN: 2358-0844 - Endereço: http://www.portalseer.ufba.br/index.php/revistaperiodicus 
alterando tanto o nome, quanto o sexo. Seu pedido ao CFM foi negado e na conclusão foi dito novamente, como no caso anterior, sobre a conduta médica somente poder realizar atos lícitos e necessários. Além disso, a retirada das glândulas mamárias foi compreendida como lesão corporal grave, segundo o artigo 129 do Código Penal. Falou-se ainda sobre a impossibilidade de mudança de sexo com a cirurgia: ainda que a mesma fosse realizada, conferir ao sujeito uma identidade diferente ao sexo designado ao nascimento seria conferir-lhe "uma 'capacidade' que ele não possui" (AMARAL, 2007, p. 112). Sendo assim, não seria possível a um sujeito alterar sua identidade e registros civis, pois isso se enquadraria no crime de falsa identidade previsto no artigo 307 do Código Penal.

O assunto das cirurgias de redesignação sexual começou a compor as pautas da mídia e, em 1995, foi realizado o primeiro debate sobre a transexualidade, cuja finalidade era a de tornar ético esse tipo de intervenção, como uma estratégia terapêutica (cf. AMARAL, 2007, p. 50). Dois anos mais tarde foi realizado o I Encontro Nacional dos Conselhos de Medicina, momento em que se retomaram essas questões e quando a plenária decidiu que a realização dessa intervenção cirúrgica se tornaria parte do fazer médico legal, uma vez que dizia respeito a um tipo de tratamento médico especial. Para que essa decisão pudesse se fazer valer era necessário, em primeiro lugar, que se criasse um embasamento legal que regulamentasse essa prática. O que foi feito através da Resolução CFM nº 1.482/97:

Esta resolução considera que a cirurgia de transgenitalização tem como motivo essencial uma "intenção de beneficência”, baseada em dois princípios: um deles, fundamentalmente terapêutico, diz respeito à "busca da integração entre o corpo e a identidade sexual psíquica do interessado"; o outro refere-se ao princípio de autonomia e justiça, ou seja, ao direito de dispor do próprio corpo e a não-discriminação no pleito à cirurgia (ARÁN, 2006, p. 59).

Nesta resolução de 1997, o CFM parte da ideia de que transexuais possuiriam um "desvio psicológico permanente de identidade sexual, com rejeição do fenótipo e tendência à automutilação e ou auto-extermínio" (CFM, 1997, p. 20.944). Rompe-se, desse modo, com a leitura feita anteriormente de que essas intervenções cirúrgicas seriam crimes de mutilação, passando a compreendê-las como práticas com fins terapêuticos. Além disso, assumem que a cirurgia de modificação dos órgãos genitais seria a fase mais importante do tratamento desse dito desvio psiquiátrico, expresso pelo termo ‘transexualismo', cujo sufixo ‘ismo’ exprime a ideia de doença. É possível ressaltar que no Brasil é utilizado o termo transexualismo, como aparece nas Resoluções do CFM, ao invés do uso do nome Transtorno de Identidade de Gênero (TIG), como contido no Manual Diagnóstico e Estatístico de Transtornos Mentais IV (DSM-IV). Vê-se, de modo geral, que as resoluções acompanham as linhas gerais do DSM sem, no entanto, incorporar literalmente os termos 
específicos, revelando idiossincrasias da interpretação brasileira.

A partir disso, o CFM decidiu permitir a realização de cirurgias de neocolpovulvoplastia, neofaloplastia e outros procedimentos sobre as gônadas e os caracteres sexuais secundários, todos eles a título experimental, em pacientes que se enquadrassem no diagnóstico de 'transexualismo', o que ficaria a cargo da equipe multidisciplinar realizar ao longo dos dois anos mínimos de acompanhamento. Para ser considerada uma pessoa transexual, o sujeito precisaria possuir ao menos essas características:

- Desconforto com o sexo anatômico natural;

- Desejo expresso de eliminar os genitais, perder as características primárias e secundárias do próprio sexo e ganhar as do sexo oposto;

- Permanência desse distúrbio de forma contínua e consistente por, no mínimo, dois anos;

- Ausência de outros transtornos mentais (CFM, 1997, p. 20.944).

A equipe de profissionais responsável pela avaliação do sujeito deveria ser composta por "médicopsiquiatra, cirurgião, psicólogo e assistente social” (CFM, 1997, p. 20.944) e as intervenções cirúrgicas somente poderiam ser feitas em hospitais públicos ou universitários onde fossem realizadas pesquisas.

Anteriormente a esta resolução do CFM, desde meados dos anos 70, transexuais já eram atendidos por médicos e psicólogos no Hospital das Clínicas da Faculdade de Medicina da Universidade de São Paulo. Com esta autorização do Conselho, pôde se juntar à equipe um urologista e cirurgiões plásticos que começaram a ofertar intervenções cirúrgicas. No entanto, foi em Campinas, também cidade do Estado de São Paulo, que a primeira transexual, Bianca Magro, foi operada gratuitamente. A cirurgia aconteceu no dia 8 de abril de 1998 no Hospital das Clínicas da Universidade Estadual de Campinas (cf. SAADEH, 2004, p. 48).

Cinco anos depois da publicação da Resolução $n^{\circ}$ 1.482/97 do CFM, ela foi substituída por uma nova, contendo mais informações e se adequando aos avanços científicos no que tange ao aprimoramento das intervenções cirúrgicas e na incorporação do uso de hormônios: em 2002, o CFM lança a Resolução n ${ }^{\mathrm{o}}$ 1.652/2002. A definição do que se entende por 'transexualismo' se manteve, bem como as condições que precisariam ser cumpridas para que o sujeito pudesse se submeter às intervenções cirúrgicas. A equipe multidisciplinar ganhou novo membro: um endocrinologista. E os hospitais, para estarem aptos a realizar estes tipos de intervenções médicas, precisariam conter todos os profissionais da equipe mínima, cuja falta de apenas um deles resultaria na paralisação da 
permissão de oferta do serviço. Além disso, esta nova resolução leva em conta o "bom resultado cirúrgico, tanto do ponto de vista estético como funcional, das neocolpovulvoplastias nos casos com indicação precisa de transformação do fenótipo masculino para feminino" (CFM, 2002, p. 80-81), bem como "as dificuldades técnicas ainda presentes para a obtenção de bom resultado tanto no aspecto estético como funcional das neofaloplastias" (CFM, 2002, p. 80-81). Com isso, se passou a autorizar a realização das cirurgias em mulheres transexuais em hospitais tanto públicos, quanto privados, sem a necessidade de estarem vinculados à pesquisa. Quanto aos homens transexuais, manteve-se o que fora decidido na resolução anterior, isto é, estes casos permaneceram associados à pesquisa, visto que se tratavam de procedimentos experimentais.

Essa Resolução foi amplamente divulgada pela mídia, o que produziu efeitos como o aumento da procura de transexuais por auxílio médico em instituições públicas (cf. ARÁN, 2006, p. 60). Com o aumento da demanda, diversos serviços interdisciplinares especializados no atendimento a essa população foram criados e organizados para oferecer suporte a ela. Desde o primeiro momento em que se legalizou esse tipo de intervenção cirúrgica e de atenção a transexuais, a estruturação da assistência pública se baseia na ideia de que a transexualidade é uma doença, um transtorno psiquiátrico. O Brasil seguiu uma tendência internacional ao adotar essa premissa, estabelecendo como condição de acesso à assistência, tanto médica, quanto jurídica, o diagnóstico de ‘transexualismo' (cf. AMARAL, 2007, p. 52). ARÁN, LIONÇO E MURTA (cf. 2009, p. 1142), também assinalaram essa questão ao discorrem sobre o contato que tiveram com alguns serviços especializados no atendimento a transexuais, quando puderam observar que geralmente a prática clínica dos profissionais acaba sendo orientada pelo viés da psiquiatrização dessas vivências.

O Conselho Nacional de Combate à Discriminação definiu, nesse período, que transexuais compõem um grupo vulnerável à exclusão social. Isso permitiu a inclusão desse grupo nas pautas dos gestores que se ocuparam de programas que visavam beneficiar pessoas LGBT - lésbicas, gays, bissexuais, transexuais e travestis (cf. AMARAL, 2007, p. 54). Em 2003, tiveram início diversas discussões sobre a possibilidade de criação de políticas públicas que fossem inclusivas para essa parcela da população. Antes se discutiam políticas focadas em doenças específicas, principalmente DST/AIDS. Atualmente houve uma ampliação das políticas públicas, que passaram a tratar a questão trans de maneira positiva devido aos movimentos sociais que começaram a trabalhar a prevenção e promoção da saúde com base nos princípios de universalidade, equidade e integralidade (cf. ARÁN; CORRÊA, 2004, p. 330). Nesse momento,

Periódicus, Salvador, n.10, v. 1, nov.2018-abr.2019 - Revista de estudos indisciplinares em gêneros e sexualidades Publicação periódica vinculada ao Grupo de Pesquisa CUS, da Universidade Federal da Bahia - UFBA ISSN: 2358-0844 - Endereço: http://www.portalseer.ufba.br/index.php/revistaperiodicus 
O Ministério da Saúde foi solicitado a tomar uma posição em relação à população LGBT, contemplando dois aspectos: que a inclusão da população LGBT no SUS se efetivasse segundo seus princípios fundamentais, a saber, universalidade, integralidade e equidade; e que o Ministério da Saúde consolidasse uma Política Nacional de Saúde para a População LGBT (ARÁN; LIONÇO; MURTA, 2009, p. 1145).

Frente a essas discussões e solicitação, o Ministério da Saúde publicou, em 2004, a Portaria ${ }^{\circ}$ 880/GM, criando, desse modo, um Comitê Técnico para a formulação da proposta de Política Nacional de Saúde da População LGBT (cf. AMARAL, 2007, p. 54). Além disso, nesse mesmo ano, o Governo Federal lançou o programa Brasil sem Homofobia - Programa de Combate à Violência e à Discriminação contra GLTB (gays, lésbicas, travestis, transexuais e bissexuais) e de Promoção da Cidadania Homossexual, mostrando que o país se comprometeria com a criação de políticas públicas que permitissem a efetividade dos direitos dessas pessoas. Esse programa surge como o resultado de mais de vinte anos de mobilização social, trazendo propostas de ações em diversos setores, entre eles saúde, educação, cultura, trabalho e segurança pública (cf. ARÁN; LIONÇO; MURTA, 2009, p. 1145).

Em novembro de 2005, aconteceu a I Jornada Nacional sobre Transexualidade e Assistência Pública no Brasil, que deu origem ao Coletivo Nacional de Transexuais (cf. ARÁN, LIONÇO; MURTA, 2009, p. 1142). Neste evento, a atenção oferecida a transexuais na época foi colocada em pauta, bem como o preconceito enfrentado cotidianamente, a violência, o mercado de trabalho e a educação. Apesar da Resolução em vigor do CFM definir alguns pontos principais aos quais todas as instituições deveriam seguir - equipe profissional multidisciplinar mínima; tempo de acompanhamento do usuário no serviço e sua idade; e modo de condução do processo - as propostas de atendimento variavam (cf. AMARAL, 2007, p. 52). Contudo, a maior parte das práticas clínicas se dava a partir da psiquiatrização da vivência transexual. Desse modo, foi colocada em questão, durante a Jornada, a necessidade do diagnóstico psiquiátrico de transexualidade para que se tivesse acesso aos serviços de saúde pública.

Em 2006, o Ministério da Saúde, através do Comitê Técnico Saúde da População GLTB, discutiu, em reunião, sobre o Processo Transexualizador no SUS. Neste encontro, estavam presentes “representantes do Ministério da Saúde, do Coletivo Nacional de Transexuais, profissionais da rede pública de saúde que atuam com transexuais e pesquisadores que se dedicam ao tema" (ARÁN, LIONÇO; MURTA, 2009, p. 1146). O Comitê reuniu essas pessoas para poderem pensar em conjunto sobre a saúde da população transexual,

problematizando a assistência desta nos serviços de saúde pública, e para definir as diretrizes da

Periódicus, Salvador, n.10, v. 1, nov.2018-abr.2019 - Revista de estudos indisciplinares em gêneros e sexualidades Publicação periódica vinculada ao Grupo de Pesquisa CUS, da Universidade Federal da Bahia - UFBA ISSN: 2358-0844 - Endereço: http://www.portalseer.ufba.br/index.php/revistaperiodicus 
assistência a transexuais no Brasil sob a perspectiva da integralidade, da equidade e da humanização da atenção (AMARAL, 2007, p. 55).

Dois anos mais tarde, em 18 de agosto de 2008, o Ministério da Saúde lançou a Portaria ${ }^{\circ}$ 1.707, instituindo o Processo Transexualizador no Sistema Único de Saúde (SUS). Nesta portaria, foi levada em consideração tanto a orientação sexual, quanto a identidade de gênero como fatores condicionantes à saúde dos sujeitos, não somente por dizerem respeito a um modo de existir e suas práticas, mas inclusive pelo fato de que a população LGBT, por não estar em conformidade com as normas sociais, ser alvo frequente de estigma, discriminação e exclusão social, o que acaba por violar os direitos humanos desses sujeitos, dentre eles "os direitos à saúde, à dignidade, à não discriminação, à autonomia e ao livre desenvolvimento da personalidade" (BRASIL, 2008a). Foi levada em conta também a Carta dos Direitos dos Usuários da Saúde, em especial a noção do atendimento humanizado e livre de discriminação que deve ser ofertado não apenas a transexuais, mas a todos os usuários dos serviços de saúde. Entende-se aqui a transexualidade como um

desejo de viver e ser aceito na condição de enquanto pessoa do sexo oposto, que em geral vem acompanhado de um mal-estar ou de sentimento de inadaptação por referência a seu próprio sexo anatômico (BRASIL, 2008a).

Tais questões precisariam ser trabalhadas e levadas em consideração durante o atendimento integral. Considerou, por fim, a Resolução $n^{\circ}$ 1.652/2002 do CFM, apresentada anteriormente, a respeito dos procedimentos de transgenitalização, bem como a necessidade de se regulamentar esse tipo de atendimento no SUS.

Ao considerar o princípio da integralidade, o Ministério da Saúde ressalta a importância de ofertar atenção ao sujeito em todos os seus aspectos, não se restringindo a oferta de procedimentos cirúrgicos. Para tanto, o atendimento deve ser humanizado e livre de discriminação, o que significa que os trabalhadores desses serviços devem respeitar às diferenças. O Ministério da Saúde, através dessa Portaria, resolveu que o Processo Transexualizador deveria "ser empreendido em serviços de referência devidamente habilitados à atenção integral à saúde aos indivíduos que dele necessitem" (BRASIL, 2008a). Estabeleceu ainda a necessidade de que fossem "organizadas e implantadas, de forma articulada entre o Ministério da Saúde, as Secretarias de Saúde dos Estados, dos Municípios e do Distrito Federal, as ações para o Processo Transexualizador no âmbito do SUS” (BRASIL, 2008a).

No dia seguinte ao lançamento dessa Portaria, em 19 de agosto de 2008, o Ministério da Saúde lançou outra, a Portaria SAS/MS n ${ }^{\circ} 457$, ainda sobre o Processo Transexualizador no SUS. Foi

Periódicus, Salvador, n.10, v. 1, nov.2018-abr.2019 - Revista de estudos indisciplinares em gêneros e sexualidades Publicação periódica vinculada ao Grupo de Pesquisa CUS, da Universidade Federal da Bahia - UFBA ISSN: 2358-0844 - Endereço: http://www.portalseer.ufba.br/index.php/revistaperiodicus 
estabelecido que a unidade hospitalar, ou seja, a unidade de atenção especializada nesse processo precisaria estar vinculada ao ensino, além de ser contratualizada com o SUS. No âmbito dessa segunda portaria, entende-se a transexualidade como um transtorno mental, como previsto na Classificação Estatística Internacional de Doenças e Problemas Relacionados à Saúde (CID-10), e sendo assim, se faz necessário o diagnóstico de ‘transexualismo' para poder ter acesso às intervenções cirúrgicas, tal qual como previsto pelo CFM. Além de estabelecer que as funções do psicólogo e do psiquiatra seriam de avaliação psicológica e de acompanhamento terapêutico (cf. BRASIL, 2008b). É esperado que os sujeitos se apresentem dentro dos moldes de uma categoria diagnóstica de 'transexualismo'. Com isso estabelece-se uma única possibilidade de vivência, desconsiderando a multiplicidade dessa experiência. Cria-se um aparato regulatório que determina os critérios sob os quais o sujeito precisa se submeter e preencher para que tenha direito de transformar seu próprio corpo, podendo chegar perto, desse modo, de algo parecido com o exercício de sua liberdade. Repetese, no âmbito da legislação brasileira aquilo que vemos aparecer nos estudos que Judith Butler (2009) empreende mais ou menos nessa mesma época.

É necessário que se estabeleça a existência de um conflito; é necessário que haja um sofrimento enorme; é necessário que haja uma identificação persistente com o outro gênero; é necessário passar um período de teste se travestindo no outro sexo durante todo o dia para que se avalie a adaptação; é necessário que haja sessões de terapia e cartas atestando o equilíbrio mental (BUTLER, 2009, p. 112).

O sujeito precisa ter a astúcia de entender quais são os parâmetros estabelecidos e se adequar a eles, como mostra Butler (2009, p. 112): "Essa pessoa tem de se submeter a rótulos e nomes, a incursões, a invasões; tem de ser medida com os parâmetros da normalidade; e tem de passar nos testes". Isso porque, ao se criar uma categoria de disfóricos de gênero, ocorre uma generalização da experiência trans. O sujeito não pode se valer da linguagem para expor e demonstrar aquilo que de fato pensa e sente, precisando renunciar sua própria liberdade para conseguir uma outra. Em última instância, a função que o diagnóstico exerce aqui não aponta para capacidade do sujeito de se adequar ou não às normas do gênero com o qual se identifica, mas, na verdade, se ele é capaz de se adequar ao discurso psiquiátrico que produz e reitera essas normas. Para muitas pessoas transexuais a única forma de ter acesso aos serviços que irão permitir uma modificação do próprio corpo é aprendendo a se apresentar em um outro discurso,

Num discurso que não é o seu - um discurso que apaga você no ato de representar você -, num discurso que exclui a linguagem que você poderia preferir usar na descrição de quem você é, como você chegou aqui e o que quer desta vida. Tal discurso exclui tudo isso, ao mesmo tempo em que apresenta a promessa

Periódicus, Salvador, n.10, v. 1, nov.2018-abr.2019 - Revista de estudos indisciplinares em gêneros e sexualidades Publicação periódica vinculada ao Grupo de Pesquisa CUS, da Universidade Federal da Bahia - UFBA ISSN: 2358-0844 - Endereço: http://www.portalseer.ufba.br/index.php/revistaperiodicus 
- se é que não é uma chantagem - de que você tem uma chance de alcançar a sua vida, o corpo e o gênero que você quer, dado que você concorde em falsificar a si mesma e, ao fazê-lo, em apoiar e ratificar o poder desse diagnóstico sobre muitas pessoas no futuro (BUTLER, 2009, p. 113).

Em 2009, o Ministério da Saúde lançou a Portaria $\mathrm{n}^{\mathrm{o}} 1.820$, dispondo sobre os direitos e deveres dos usuários da saúde. Dentre os direitos estava um especialmente importante para transexuais e travestis: ao falar da necessidade de oferta de um atendimento humanizado e livre de discriminação, o Ministério da Saúde garantiu o direito do uso do nome social dos usuários dos serviços de saúde, além de assegurar o uso do nome de preferência do sujeito.

No ano seguinte, em setembro de 2010, o CFM lançou nova Resolução: $n^{\circ} 1.955$, a respeito da cirurgia de 'transgenitalismo', revogando a anterior $\left(\mathrm{n}^{\circ} 1.652 / 2002\right)$, que está em vigor até a data de confecção desse artigo. Considerando as três Resoluções do CFM acerca desses procedimentos, nada mudou na definição dada sobre o que é a transexualidade, entendendo ainda ser o "paciente transexual portador de desvio psicológico permanente de identidade sexual, com rejeição do fenótipo e tendência à automutilação e/ou autoextermínio" (CFM, 2010, p. 109-110). Além disso, a cirurgia de redesignação de sexo continua a ser considerada a etapa mais importante de todo o processo. E os critérios que precisam ser cumpridos para ter acesso às intervenções médicas (de idade, tempo de acompanhamento e diagnóstico de transtorno de identidade de gênero) permaneceram os mesmos.

Em uma análise entre as últimas duas Resoluções do CFM, de 2002 e de 2010, permanecem iguais as dificuldades em se obter bons resultados estéticos e funcionais nas intervenções realizadas nos órgãos genitais de homens transexuais, ou seja, nas neofaloplastias. Anteriormente, os procedimentos complementares sobre as gônadas e caracteres sexuais secundários em homens transexuais ainda eram autorizados apenas a título experimental, deixando de ser na resolução mais recente, permanecendo apenas a neofaloplastia. E, por fim, foi retirada a especificidade do local a serem feitos os procedimentos cirúrgicos quanto a ser ou não em instituições voltadas à pesquisa, tratando agora apenas da necessidade de serem em hospitais registrados no Conselho Regional de Medicina e que possuam todos os prérequisitos estabelecidos pela Resolução, entre eles, a equipe multidisciplinar.

Frente a essa publicação do CFM e a necessidade de ampliar o Processo Transexualizador no SUS, o Ministério da Saúde lançou, em 19 de novembro de 2013, a Portaria n ${ }^{\circ} 2.803$, em vigor no momento da confecção do presente artigo. Levando em conta alguns pontos, entre eles: (1) as Portarias $n^{\circ} 1.820$ e $n^{\circ} 2.836$ que tratam do direito do uso do nome social no SUS e da Política Nacional de Saúde Integral de Lésbicas, Gays, Bissexuais, Travestis e Transexuais, respectivamente;

Periódicus, Salvador, n.10, v. 1, nov.2018-abr.2019 - Revista de estudos indisciplinares em gêneros e sexualidades Publicação periódica vinculada ao Grupo de Pesquisa CUS, da Universidade Federal da Bahia - UFBA ISSN: 2358-0844 - Endereço: http://www.portalseer.ufba.br/index.php/revistaperiodicus 
(2) a necessidade de "identificar, estruturar, ampliar e aprimorar a rede de atenção à saúde e a linha de cuidado de transexuais e travestis" (BRASIL, 2013), em especial para os usuários que solicitem adequação para o fenótipo masculino. O Ministério da Saúde resolve então pela ampliação do Processo Transexualizador no SUS e entende como diretrizes para a assistência as seguintes questões: a integralidade na atenção a transexuais e travestis, no mesmo sentido da versão anterior, na qual se faz necessário um atendimento que extrapole as intervenções somáticas; o trabalho que precisa ser executado a partir de uma equipe multiprofissional e interdisciplinar; e o acolhimento e atendimento humanizados e livres de discriminação, tal qual a versão anterior (cf. BRASIL, 2013).

A linha de cuidado da atenção a transexuais e travestis é estruturada por dois componentes: a atenção básica e a atenção especializada (ambulatorial e hospitalar). A atenção básica é a porta de entrada do SUS, ou seja, é o primeiro serviço que o usuário pode fazer uso. É o local onde será feita a coordenação do cuidado a ser oferecido, além de ser responsável pela atenção contínua da população da sua região. A atenção básica deve garantir o cuidado integral, através do acolhimento humanizado, do uso do nome social do usuário e do encaminhamento adequado ao Serviço de Atenção Especializada. A atenção especializada, por outro lado,

É um conjunto de diversos pontos de atenção com diferentes densidades tecnológicas para a realização de ações e serviços de urgência, ambulatorial especializado e hospitalar, apoiando e complementando os serviços da atenção básica de forma resolutiva e em tempo oportuno (BRASIL, 2013).

Ao oferecer um cuidado integral, as ações ambulatoriais devem se responsabilizar pelo acompanhamento clínico pré e pós-operatório, além da hormonioterapia. Para tal, são necessárias condições técnicas condizentes e a presença da equipe profissional mínima, a saber, "1 psiquiatra ou 1 psicólogo, 1 assistente social, 1 endocrinologista ou 1 clínico geral e 1 enfermeiro" (BRASIL, 2013). A modalidade hospitalar, por sua vez, é responsável pela realização das intervenções cirúrgicas e também pelo acompanhamento pré e pós-operatório. A equipe mínima estabelecida para esta modalidade é, segundo a Portaria n ${ }^{\mathrm{o}} 2.803$,

1 médico urologista, ou 1 ginecologista ou 1 cirurgião plástico, com título de especialista da respectiva especialidade [...]. A Equipe de Enfermagem deve contar com enfermeiros e técnicos de enfermagem dimensionados conforme Resolução COFEN 293 de 2004 [...] deverá contar no mínimo: 1 psiquiatra ou 1 um psicólogo, 1 endocrinologista, e 1 assistente social (BRASIL, 2013).

Apesar do Ministério da Saúde ofertar serviços em nível hospitalar, a Portaria considera o fato de que nem todas as pessoas transexuais e travestis desejam realizar algum tipo de cirurgia, sendo

Periódicus, Salvador, n.10, v. 1, nov.2018-abr.2019 - Revista de estudos indisciplinares em gêneros e sexualidades Publicação periódica vinculada ao Grupo de Pesquisa CUS, da Universidade Federal da Bahia - UFBA ISSN: 2358-0844 - Endereço: http://www.portalseer.ufba.br/index.php/revistaperiodicus 
possível, portanto, o uso apenas dos serviços ambulatoriais para o acompanhamento clínico e hormonioterapia, caso requerido. Ainda, com base na última Resolução do CFM, define que a hormonioterapia pode ser iniciada somente a partir dos 18 anos e as intervenções cirúrgicas aos 21, após dois anos de acompanhamento profissional multidisciplinar e com indicação específica.

A importância dos profissionais da psicologia no atendimento a transexuais é reconhecida pelo Conselho Federal de Medicina desde 1997, ano da publicação da primeira Resolução que autorizou intervenções cirúrgicas. Foi também reconhecida pelo Ministério da Saúde em 2008, se mantendo na vigente Portaria de 2013. Contudo, apesar do entendimento médico e do próprio Ministério da Saúde da transexualidade enquanto doença, o Conselho Federal de Psicologia (CFP) se posicionou de maneira contrária a esse viés patológico. Em julho de 2013, o CFP lançou uma Nota Técnica sobre Processo Transexualizador e Demais Formas de Assistência às Pessoas Trans, na qual apresentou alguns acontecimentos importantes da história do Brasil, entre eles: a Constituição Federal Brasileira de 1988 que prevê a saúde enquanto um direito social de todos os brasileiros, sem qualquer tipo de discriminação e respeitando os direitos humanos; a Lei no 8.080 de 1990, lembrando os princípios que foram instituídos pelo SUS - universalidade, integralidade, autonomia e igualdade; e a presença do psicólogo como profissional componente da equipe multidisciplinar no atendimento a transexuais nos serviços de saúde do SUS, segundo a Portaria nº 457/2008 (cf. CFP, 2013, p. 1). A partir desse breve histórico, o CFP considerou que é função do psicólogo, no atendimento a transexuais, garantir o respeito à sua dignidade, bem como o seu acesso aos serviços públicos de saúde, entendendo que

a transexualidade e a travestilidade não constituem condição psicopatológica, ainda que não reproduzam a concepção normativa de que deve haver uma coerência entre sexo biológico/gênero/desejo sexual (CFP, 2013, p. 2).

Ao citar um trecho da Portaria $n^{0} 1.707 / 2008$, em que é dito sobre a necessidade do acompanhamento psicoterápico a pessoal transexual antes e após sua tomada de decisão quanto às intervenções cirúrgicas, conclui que o papel do psicólogo é amplo em todo o processo, não se restringindo a este ponto em que o sujeito toma a decisão de fazer ou não modificações corporais. $\mathrm{O}$ objetivo da assistência psicológica é, portanto, o de promover qualidade de vida, o que deve ser feito através do acolhimento e do entendimento de que a transexualidade é apenas uma dentre as "múltiplas possibilidades de vivência da sexualidade humana" (CFP, 2013, p. 2). É ainda necessário que se leve em conta que os discursos são atravessados por diversas e diferentes variáveis e que é direito de transexuais procurar pelos serviços psicológicos não apenas em centros especializados, mas como em qualquer outro lugar, seja da rede pública ou privada.

Periódicus, Salvador, n.10, v. 1, nov.2018-abr.2019 - Revista de estudos indisciplinares em gêneros e sexualidades Publicação periódica vinculada ao Grupo de Pesquisa CUS, da Universidade Federal da Bahia - UFBA ISSN: 2358-0844 - Endereço: http://www.portalseer.ufba.br/index.php/revistaperiodicus 
Ao considerar todas essas questões, o CFP apresentou algumas orientações para a prática psicológica: é função do psicólogo respeitar a diversidade subjetiva da pessoa que decidir se submeter às intervenções corporais, garantindo-lhe seu direito à saúde integral e ao atendimento humanizado e livre de discriminação, tal qual preconizado pelo SUS. A assistência psicológica deve servir como uma ferramenta de apoio ao sujeito durante todo o processo, auxiliando-o a confirmar a autenticidade da sua demanda ao lhe oferecer informações acerca da diversidade de gênero e das consequências dos diferentes tipos de intervenções corporais, em um exercício de promoção da autonomia, não devendo, portanto, "se orientar por um modelo patologizado ou corretivo da transexualidade e de outras vivências trans" (CFP, 2013, p. 3). É fundamental que o sujeito compreenda que o projeto terapêutico é singular e flexível, devendo ser construído de acordo com suas necessidades. O acompanhamento psicológico a transexuais e travestis preconizado pelo Ministério da Saúde deve ser feito através do acolhimento, da escuta e, em alguns casos, da avaliação psicológica. Quando esta última se fizer necessária é importante que o psicólogo considere diferentes aspectos e inclua na avaliação informações que não necessariamente tenham a ver com a transexualidade do sujeito, mas que sejam relevantes para a promoção de um atendimento integral. E, por fim, é necessário que o profissional da psicologia faça uso de "pesquisas e estudos culturais na área de gênero e sexualidade na tentativa de buscar um respaldo teórico para entendimento desse contexto social para superação da heteronormatividade" (CFP, 2013, p. 3).

\section{A questão trans na atualidade brasileira}

Apresentamos, em um primeiro momento, alguns dos acontecimentos relevantes que marcam a história da transexualidade no Brasil e nos permitem entender, em partes, como se deram processos jurídicos e sociais referentes a esta parcela da população. Neste momento, iremos tratar dos dados mais recentes, apresentando parte da realidade da população trans como um todo, incluindo não apenas transexuais, mas também travestis, no cenário brasileiro nos últimos anos, evidenciando a existência do preconceito, violência e ausência de informações oficiais e dados estatísticos. A travestilidade pode ser definida como "pessoas que vivenciam papéis de gênero feminino, mas não se reconhecem como homens ou como mulheres, mas como membros de um terceiro gênero ou de um não-gênero" (JESUS, 2012, p. 17). Apesar de tratar-se de vivências distintas, serão apresentados dados referentes a estes dois grupos, pois, na maioria dos casos, são expressos conjuntamente e às vezes até indistintamente.

Verificamos que todo esse contexto gira em torno de um discurso de ódio que há muito se reproduz acerca das questões que envolvem a população LGBT (lésbicas, gays, bissexuais, travestis

Periódicus, Salvador, n.10, v. 1, nov.2018-abr.2019 - Revista de estudos indisciplinares em gêneros e sexualidades Publicação periódica vinculada ao Grupo de Pesquisa CUS, da Universidade Federal da Bahia - UFBA ISSN: 2358-0844 - Endereço: http://www.portalseer.ufba.br/index.php/revistaperiodicus 
e transexuais) como um todo. Pode-se definir operacionalmente o discurso de ódio como um discurso que "apresenta como elemento central a expressão do pensamento que desqualifica, humilha e inferioriza indivíduos e grupos sociais" (FREITAS; CASTRO, 2013, p. 344). Esse discurso tem como efeito, de um lado, a legitimação da violência sobre esse grupo - crimes de ódio - e, de outro, a invisibilização desses sujeitos em uma discursividade que poderíamos classificar como oficial. Os crimes de ódio são, segundo Jesus

motivados por preconceito contra alguma característica da pessoa agredida que a identifique como parte de um grupo discriminado, socialmente desprotegido, e caracterizados pela forma hedionda como são executados (JESUS, 2013, p. 113).

Serão explorados aqui os efeitos desses discursos sob as pessoas transexuais e travestis, ressaltando que ainda que se denominem diferentemente esses grupos, em geral se encontram na mira de um mesmo discurso. Buscaremos demonstrar isso a partir de consulta de notícias e materiais publicados em meios de comunicação e artigos científicos.

Estamos diante de uma realidade ainda precária e preocupante. A violência contra as pessoas trans é estrutural e sistemática, acontecendo em diferentes lugares, a começar pela sua própria casa. Praticamente não existem dados estatísticos que retratam especificamente a realidade dessas vivências, o que se encontra - quando se encontra - são informações sobre toda a comunidade LGBT. Não há dados sobre transexuais e travestis nos órgãos oficiais do Brasil, entre eles o IBGE e os Ministérios da Saúde e da Justiça, e os poucos encontrados não são imediatamente acessíveis. As informações que se tem são provenientes do Ministério dos Direitos Humanos e de Organizações Nacionais e Internacionais, como a Transgender Europe, Grupo Gay da Bahia e a Associação Nacional de Travestis e Transexuais (Antra). Somado a isso, existem diferentes matérias sobre esse assunto publicadas na imprensa, que se valem, por vezes, dessas mesmas organizações. O próprio fato de não existirem dados oficiais sobre a realidade desses sujeitos no Brasil revela o apagamento dessa população e, de certa forma, a transfobia dos diferentes órgãos, que tomam como dado apenas o dito sexo biológico, de modo que se pode somente nascer e morrer homem ou mulher, de acordo com o que o médico determinou ao nascimento. Neste tópico será feito uso das informações recolhidas dessas organizações e das matérias encontradas na mídia a fim de retratar parte da realidade brasileira.

As organizações citadas se valem de relatos de casos e publicações da imprensa para formar seus números, enquanto que o Ministério dos Direitos Humanos, até o momento em que o presente texto foi escrito, possui um Departamento de Ouvidoria Nacional vinculado à Secretaria de Direitos 
Humanos da Presidência da República (SDH/PR), que pode ser acessado através do Disque 100. Esse departamento tem a competência de:

Receber, examinar e encaminhar denúncias e reclamações, atuar na resolução de tensões e conflitos sociais que envolvam violações de direitos humanos, além de orientar e adotar providências para o tratamento dos casos de violação de direitos humanos, podendo agir de ofício e atuar diretamente ou em articulação com outros órgãos públicos e organizações da sociedade (PORTAL BRASIL, 2017).

Essa Secretaria lançou, em janeiro de 2017, um balanço geral dos dados colhidos entre os anos 2011 a 2016 a respeito das violações dos direitos da população LGBT. Ao longo desse período foram 10.757 denúncias feitas, sendo 1.876 somente em 2016. Foram classificados diferentes tipos de violência, o que acresceu o número, visto que em uma única ligação poder-se-ia denunciar diferentes tipos de violência, entre elas: discriminação (1.458), negligência (74), violência física (385), violência institucional (80), violência psicológica (861) e violência sexual (28) - dados de 2016 (cf. PORTAL BRASIL, 2016a). É possível, contudo, que se tenha uma breve ideia da quantidade de denúncias feitas referentes à violência contra transexuais e travestis, pois a Secretaria de Direitos Humanos especificou uma categoria de violência por identidade de gênero. Entre 2011 a 2016 foram 1.344 denúncias, sendo 184 registradas em 2016 (cf. PORTAL BRASIL, 2016a).

Para a promoção de saúde é fundamental um ambiente familiar adequado e uma moradia segura, entretanto, diversas pessoas transexuais e travestis relatam não encontrar em casa suporte necessário, sendo vítimas, muitas vezes, de diversos tipos de violência pelos próprios familiares. Essa realidade aparece expressivamente nos dados desse levantamento da SDH/PR: no período de 2011 a 2016, foram registradas 2.283 denúncias de violência que aconteceram na própria casa da vítima (cf. PORTAL BRASIL, 2016a). É importante lembrar que esses dados são referentes às denúncias feitas e que não necessariamente expressam a realidade, uma vez que muitos casos não são reportados ou denunciados.

De acordo com uma reportagem do Correio Braziliense, pode-se verificar a passagem do discurso de ódio à violência física propriamente dita através do fato de que "constantes manifestações de preconceito, bullying, ameaças e agressões físicas fazem parte da rotina de alunos LGBT nas escolas brasileiras" (CUNHA; HANNA, 2017). Em entrevista com 1.016 estudantes, pertencente a um estudo publicado em dezembro de 2016, a Secretaria de Educação da Associação Brasileira de Lésbicas, Gays, Bissexuais e Transexuais (ABLGBT) chegou à conclusão que 73\% dos alunos que não se declaram heterossexuais já sofreram violência verbal na escola, sendo que 1 em cada 4 sofreu violência física também. Desta amostra, 55\% disseram ter ouvido na escola, durante o ano anterior, 
comentários negativos sobre pessoas transexuais. Frente a esta situação, 45\% das pessoas afirmaram sentir-se inseguras quanto sua identidade e expressão de gênero. Ainda sobre esse assunto, a reportagem traz dados de outra pesquisa, esta

Conduzida pelo defensor público João Paulo Carvalho Dias, presidente da Comissão de Diversidade Sexual da Ordem dos Advogados do Brasil (OAB), estima que o país concentre $82 \%$ de evasão escolar de travestis e transexuais, uma situação que aumenta a vulnerabilidade dessa população e favorece os altos índices de violência que ela sofre (CUNHA; HANNA, 2017).

Uma das maneiras possíveis de se lidar com essa realidade e produzir mudanças é através de discussões sobre gênero e orientação sexual nas escolas, ensinando aos alunos o respeito às diferenças. Contudo, ainda existem diversos grupos de pessoas que se posicionam contrariamente a este tipo de medida: em sete cidades brasileiras, são elas Novo Gama (GO), Cascavel (PR), Paranaguá (PR), Blumenau (SC), Palmas (TO), Tubarão (SC) e Ipatinga (MG), foram instauradas leis municipais com o objetivo de impedir essas discussões (cf. LUCON, 2017a). Posteriormente, Volta Redonda (RJ) também integrou este grupo (cf. PEREIRA, 2017). O então procurador-geral da república, Rodrigo Janot, em contrapartida, apresentou ações que colocam em questão esse tipo de lei municipal e pediu pela revogação das mesmas, afirmando que elas são baseadas em questões religiosas e contribuem para a manutenção de um ambiente de sofrimento, violência, marginalização e evasão escolar de pessoas LGBT. Essas leis, segundo Janot,

Violam dispositivos constitucionais relativos ao direito à igualdade, à proibição de censura em atividades culturais, ao devido processo legal, à laicidade do Estado, à exclusividade da União de legislar sobre diretrizes e bases da educação, ao pluralismo de ideias e de concepções pedagógicas, e ao direito à liberdade de aprender, ensinar, pesquisar e divulgar o pensamento, a arte e o saber (LUCON, 2017a).

Contudo, o relator da lei da cidade de Goiás conseguiu barrar o prosseguimento da ação, alegando que o Ministério Público precisaria ter questionado a lei municipal no Tribunal de Justiça de Goiás primeiro. Já no município de Volta Redonda foi instaurada uma lei - 5.165/2015 - que declarava: "fica vedada a implantação da política de ideologia de gênero nos estabelecimentos e ensino do município de Volta Redonda" (PEREIRA, 2017). Esta foi considerada inconstitucional pelo Tribunal de Justiça do Rio de Janeiro (TJ-RJ), que a revogou em 17 de abril de 2017. O documento formulado pelo TJ diz que

A Câmara Municipal de Volta Redonda, ao editar a referida norma jurídica, vedando a implantação da política de ideologia de gênero nos estabelecimentos de ensino do Município de Volta Redonda, violou, de uma só tacada, o princípio constitucional da igualdade no aspecto estrutural (direito a não 
discriminação), o direito fundamental à diferença, o modelo republicano do Estado brasileiro, baseado no pluralismo político, e o princípio da laicidade estatal (PEREIRA, 2017).

Pessoas transexuais e travestis sofrem formas de violência que podem, em diversos casos, levar à expulsão de casa e à evasão escolar. Se mesmo nos casos em que se tornam graduados e aptos a exercerem diferentes profissões encontram-se dificuldades para conseguir um emprego por conta de sua identidade de gênero, aqueles que nem ao menos possuem formação escolar básica são duplamente excluídos. Essa associação entre a falta de apoio familiar, a privação da possibilidade de estudar e o preconceito social acabam por delegar a prostituição como único meio de sobrevivência possível (cf. GONÇALVES, 2017). Angela Lopes, mulher transexual e ex-diretora da Divisão de Políticas para a Diversidade Sexual de São Carlos, criticou em uma matéria para o Estadão:

Você tem mais de 90\%, isso é um dado da ANTRA (Associação Nacional de Travestis e Transexuais), mais de $90 \%$ de travestis e transexuais vivendo unicamente da prostituição. Isso é um aprisionamento social. A sociedade designou que esses seres humanos não possuem potencialidades para exercer outra função que não seja o trabalho sexual, aí elas são colocadas como objeto (AMCHAM, 2017).

Os índices de violência contra pessoas trans e de gênero diverso, não apenas no Brasil, mas como em toda a América Latina, são expressivos devido, entre outras coisas, à vulnerabilidade desses sujeitos ao trabalharem se prostituindo (cf. CUNHA 2017). Sendo assim, um dos maiores obstáculos a ser combatido para a modificação dessa realidade é a exclusão do mercado de trabalho desses sujeitos.

A violência contra transexuais e travestis acontece também nas ruas: foram 2.783 denúncias feitas através do Disque 100 no período de 2011 a 2016 de casos como esse contra a população LGBT (cf. PORTAL BRASIL, 2016a). Vivemos no país que mais mata transexuais e travestis no mundo: entre 1 de janeiro de 2008 à 31 de dezembro de 2015 foram 802 assassinatos só no Brasil, seguido pelo México com 229 e pelos Estados Unidos com 132 (cf. TRANSGENDER EUROPE, 2016). Sendo assim, o número de casos relatados no Brasil é maior do que o triplo do país que fícou em segundo lugar, o México. Ao todo foram 2.016 mortes em 65 países, sendo que 65\% dessas pessoas se prostituíam.

Benevides, pesquisadora da Antra relatou, através do Mapa de Assassinatos de Pessoas Trans no Brasil, 179 assassinatos de transexuais e travestis durante o ano de 2017 (cf. BENEVIDES, 2017). Todos esses dados obtidos pelas diferentes instituições são baseados em casos reportados pela mídia ou pelas redes sociais, visto que não há, no Brasil, a tipificação de transfobia ou LGBTfobia no registro desses crimes, além da subnotificação que ocorre quando veículos de comunicação tratam

Periódicus, Salvador, n.10, v. 1, nov.2018-abr.2019 - Revista de estudos indisciplinares em gêneros e sexualidades Publicação periódica vinculada ao Grupo de Pesquisa CUS, da Universidade Federal da Bahia - UFBA ISSN: 2358-0844 - Endereço: http://www.portalseer.ufba.br/index.php/revistaperiodicus 
esses casos como assassinatos de gays ou lésbicas, "invisibilizando a identidade de gênero e o nome social das pessoas trans - sobretudo a dos homens trans" (LUCON, 2017b). Os números podem, dessa forma, ser ainda mais expressivos. Frente a essa realidade, a expectativa de vida dessa parcela da população é baixíssima, de acordo com dados do Grupo Gay da Bahia é de 35 anos, menor que a metade do restante da população, que é de 75 anos (cf. G1, 2017).

Em uma realidade de exclusão, preconceito e violência, muitas pessoas transexuais e travestis tentam e até cometem suicídio. Nos Estados Unidos $41 \%$ de transexuais tiveram pelo menos uma tentativa, enquanto que o índice do restante da população é de 1,2\%, como mostra a National Gay and Lesbian Task Force (cf. LUCON, 2017c). Em uma pesquisa realizada pela Universidade Maurício de Nassau acerca desse assunto, chegou-se à conclusão que

66,4\% dos homens trans brasileiros pensaram em suicídio, que 41,5\% já tentaram pelo menos uma vez e $28,2 \%$ tiveram duas tentativas. A população em geral, tem o índice de $3 \%$ de uma tentativa de suicídio, informa o CVV (LUCON, 2017c).

Ainda se faz necessário a criação de políticas públicas que sejam eficazes na proteção e garantia de direitos dessa população. Durante anos os movimentos sociais que lutam pelas causas trans buscaram o direito de alteração dos seus registros civis, tanto em relação ao nome, quanto em relação ao sexo, pois além de ter sua identidade garantida nesses registros oficiais, poder-se-ia evitar situações discriminatórias, pois desse modo a sua imagem e nome estariam em acordo com sua expressão de gênero. Essa é uma conquista recente, a qual tratar-se-á adiante. Antes da decisão do Supremo Tribunal Federal (STF), um dos meios possíveis para se obter a mudança do nome era através da inclusão do nome social no Cadastro de Pessoas Físicas (CPF), um processo simples, gratuito e que não exigia ação judicial. Quando requerido, o nome social aparecia em destaque acima do nome de registro. De acordo com um portal de notícia, "a Norma de Execução que autoriza tal inclusão é a COCAD Número 02 de 28/06/2017 e teve embasamento no Decreto no 8.727, de 28 de abril de 2016" (LUCON, 2017d). Neste decreto, a ex-presidente Dilma Rousseff estabelece no artigo $6^{\circ}$ :

A pessoa travesti ou transexual poderá requerer, a qualquer tempo, a inclusão de seu nome social em documentos oficiais e nos registros dos sistemas de informação, de cadastros, de programas, de serviços, de fichas, de formulários, de prontuários e congêneres dos órgãos e das entidades da administração pública federal direta, autárquica e fundacional (BRASIL, 2016).

A possibilidade da inclusão e do uso do nome social foi, para a travesti e coordenadora-geral de Promoção dos Direitos LGBT da Secretaria Especial de Direitos Humanos, Symmy Larrat, uma

Periódicus, Salvador, n.10, v. 1, nov.2018-abr.2019 - Revista de estudos indisciplinares em gêneros e sexualidades Publicação periódica vinculada ao Grupo de Pesquisa CUS, da Universidade Federal da Bahia - UFBA ISSN: 2358-0844 - Endereço: http://www.portalseer.ufba.br/index.php/revistaperiodicus 
medida criada para poder "suprir a ausência de legislação que reconheça a identidade de gênero das pessoas" (PORTAL BRASIL, 2016b), funcionando como um paliativo criado pelo Executivo para suprir uma falta do Legislativo nesse reconhecimento.

Foi no dia 2 de março de 2018, que o STF decidiu, durante o julgamento da Ação Direta de Inconstitucionalidade (ADI) 4275, que a alteração de nome e sexo nos registros civis é direito de transexuais e travestis. Nessa decisão ficou estabelecido que para a mudança dos registros não se faz mais necessária a realização de cirurgia de redesignação sexual, a apresentação de laudo médico e uma autorização judicial. Isso quer dizer que "os processos de retificação do registro civil vão ocorrer por via administrativa, sem a necessidade de judicialização" (ISTOÉ, 2018). Não é mais preciso, portanto, comprovar a identidade psicossocial do sujeito, bastando uma autodeclaração. Antes dessa decisão o processo de retificação dos registros civis era demorado e mais complicado, pois requeria diversos documentos, além da abertura de um processo judicial. A pedagoga trans Thiffany Odara lembra que não bastava

\footnotetext{
Chegar na Defensoria Pública e entregar sua identidade e CPF. Você tinha que apresentar a certidão de nascimento original, certidão negativa criminal municipal, estadual e federal, títulos, quitação eleitoral, antecedentes criminais, fotos que comprovassem que no seu convívio social você era conhecida pelo nome 'de guerra', tirando prints do Facebook e de e-mail, por exemplo, além de testemunhas que comprovassem como eu era chamada (ISTOÉ, 2018).
}

Keila Simpson, presidente da Antra, afirmou ainda que o tempo médio dos processos, até a decisão final, era de 8 meses a 2 anos e, em geral, a retificação era somente do nome e não do sexo (ISTOÉ, 2018). De modo que situações de constrangimento e preconceito permaneciam, pois, o sexo estava ainda em desacordo com a expressão de gênero dos sujeitos.

Nossa breve pesquisa indicou quão difícil é levantar dados sobre essa população, pois os dados oficiais consideram apenas os registros de nascimento das pessoas, o que produz uma invisibilização de transexuais e travestis, impossibilitando a produção de dados estatísticos. Sendo assim, com essa decisão do STF torna-se possível o levantamento de dados oficiais a respeito da realidade da população trans no Brasil. Keila Simpson defende que o objetivo central após essa conquista de direito é o de pedir novamente ao Instituto Brasileiro de Geografia e Estatística (IBGE), a categorização da população de travestis e transexuais (cf. ISTOÉ, 2018). Em suas palavras: “Se o Supremo já decidiu que a gente vai ter a retificação de nome, essa ação de pautar o IBGE para colocar no Censo a nossa categoria é a nossa meta a partir de agora” (ISTOÉ, 2018).

Periódicus, Salvador, n.10, v. 1, nov.2018-abr.2019 - Revista de estudos indisciplinares em gêneros e sexualidades Publicação periódica vinculada ao Grupo de Pesquisa CUS, da Universidade Federal da Bahia - UFBA ISSN: 2358-0844 - Endereço: http://www.portalseer.ufba.br/index.php/revistaperiodicus 


\section{Considerações Finais}

As discussões de questões referentes a este tema são relativamente recentes no Brasil. Percorremos, ao longo do artigo, por alguns pontos específicos dessa história, desde a luta para tornar legal o atendimento médico especializado a transexuais e travestis, até suas conquistas de direitos e inclusão no SUS. Para tratar dessas questões é preciso fazer uma análise multidisciplinar e ampliada, visto que elas envolvem diversos âmbitos e instâncias do saber. Debates a respeito de diferentes posicionamentos de profissionais de várias áreas que lidam com essa problemática ainda se fazem presentes na atualidade.

Vivemos um momento em que o discurso de ódio que sustenta a violência e os crimes de ódio ganham novas plataformas de multiplicação, dadas as novas formas de tecnologia e redes sociais. Jesus $(2013$, p. 117) chega à conclusão de que os crimes de ódio cometidos contra transexuais e travestis podem ser classificados como genocídio, ressaltando que esse termo contemporaneamente adquiriu um sentido muito amplo, sendo necessário retomar sua acepção original. Desse modo, aponta para a etiologia do termo genocídio: segundo a autora este termo provém da "união dos termos gregos genos (grupo) e cide (matar). Etimologicamente, significa 'matar um grupo"” (JESUS, 2013, p. 117). Em 1948 ocorreu a Assembleia Geral das Nações Unidas quando se definiu o genocídio como todo e qualquer ato cometido

Com a intenção de destruir, no todo ou em parte, um grupo nacional, étnico, racial ou religioso, tais como: a) Assassinato de membros do grupo; b) Atentado grave à integridade física e mental de membros do grupo; c) Submissão deliberada do grupo a condições de existência que acarretarão a sua destruição física, total ou parcial; d) Medidas destinadas a impedir os nascimentos no seio do grupo; e) Transferência forçada das crianças do grupo para outro grupo (ONU, 1948, p. 1).

A violência estrutural contra transexuais e travestis pode ser descrita dentro dessa definição apresentada pela Organização das Nações Unidas (ONU), especialmente no que tange as alíneas a, b e c. Com relação a alínea $\mathrm{d}$, até há pouquíssimo tempo se verificava no Brasil: para a retificação dos documentos oficiais era necessário, em muitos casos, que esses sujeitos se submetessem à intervenções cirúrgicas de transformação corporal dentro de uma lógica de "mudança de sexo". Esta exigência se apresentava como uma violência contra esses sujeitos, pois mesmo aqueles que não desejassem modificar seus corpos precisariam fazê-lo para ter sua identidade reconhecida pelo Estado e pela sociedade. O que se apresenta como uma violência institucional e "uma prática eugenista de esterilização forçada contra um grupo populacional, em pleno século XXI” (JESUS,

Periódicus, Salvador, n.10, v. 1, nov.2018-abr.2019 - Revista de estudos indisciplinares em gêneros e sexualidades Publicação periódica vinculada ao Grupo de Pesquisa CUS, da Universidade Federal da Bahia - UFBA ISSN: 2358-0844 - Endereço: http://www.portalseer.ufba.br/index.php/revistaperiodicus 
2013, p. 118). Nesse sentido,

Em virtude da sua expressividade numérica com relação a outros países; do seu enquadramento como crime de ódio, dada sua natureza de cunho discriminatório; da sua identificação com a maioria dos atos relacionados a genocídios; e com base em uma perspectiva teórica útil, o assassinato de pessoas transgênero no Brasil pode ser designado como um genocídio (JESUS, 2013, p. 118).

É preciso criar meios de monitorar e avaliar com mais precisão esses efeitos para que seja possível anulá-los. Com o reconhecimento dessa parcela da população como uma minoria vulnerável, pode-se lançar um olhar mais atento à sua realidade e necessidades. Isto é possível, dentre outras coisas, graças aos movimentos sociais que lutaram e continuam lutando pela ampliação e conquista de novos direitos. O que é possível se verificar, por exemplo, com uma grande vitória recente: a possibilidade de mudança de nome e sexo no registro civil, sem que para isso precisem se submeter a intervenções cirúrgicas e apresentar laudo médico. Contudo, frente aos dados apresentados anteriormente e até mesmo a ausência e inexistência de muitos que serão necessários aferir, fica evidente que a realidade brasileira ainda é precária no que tange a essas questões e precisa de profundas transformações para que possa se tornar um lugar seguro e igualitário, livre de preconceito e violência contra pessoas transexuais e travestis. Para isso é fundamental que gestores e instituições criem e ampliem estratégias que combatam os discursos de ódio, protejam a existência dessas experiências e lhes assegurem direitos básicos que todos os brasileiros possuem, com o objetivo de produzir mudanças em diferentes âmbitos: familiar, escolar, no mercado de trabalho, na saúde, entre outros.

\section{Referências}

AMARAL, Daniela Murta. A psiquiatrização da transexualidade: análise dos efeitos do diagnóstico de transtorno de identidade de gênero nas práticas de saúde. 2007. 129fs. Tese (Mestrado em Saúde Coletiva) - Instituto de Medicina Social, Universidade do Estado do Rio de Janeiro, Rio de Janeiro, 2007.

AMCHAM. 2017. Transgênero, transexual, travesti: os desafios para a inclusão do grupo no mercado de trabalho. Disponível em: <https://bit.ly/2HA1Xi9>. Acesso em 02 mai 2018.

ARÁN, Márcia; CORRÊA, Marilena. Sexualidade e Política na Cultura Contemporânea: o Reconhecimento Social e Jurídico do Casal Homossexual. Physis: Rev. Saúde Coletiva, Rio de Janeiro, v. 14, n. 12, p. 329-341, 2004.

ARÁN, Márcia. A Transexualidade e a Gramática Normativa do Sistema Sexo-Gênero. Ágora, Rio de Janeiro, v. 9, n. 1, p. 49-63, jan./jun. 2006.

ARÁN, Márcia; LIONÇO, Tatiana; MURTA, Daniela. Transexualidade e saúde pública no Brasil. Ciência \& Saúde Coletiva, Rio de Janeiro, v. 14, n.14, p. 1141-1149, 2009.

Periódicus, Salvador, n.10, v. 1, nov.2018-abr.2019 - Revista de estudos indisciplinares em gêneros e sexualidades Publicação periódica vinculada ao Grupo de Pesquisa CUS, da Universidade Federal da Bahia - UFBA ISSN: 2358-0844 - Endereço: http://www.portalseer.ufba.br/index.php/revistaperiodicus 
BENEVIDES, Bruna. 2017. Mapa dos casos de assassinatos de Travestis, Mulheres Transexuais e Homens Transexuais no território brasileiro no ano de 2017. Disponível em: $<$ https://www.google.com/maps/d/viewer?mid=1yMKNg31SYjDAS0NZwH1jJ0apFQ\&hl=en_US\&1l=-17.152191563664402\%2C-45.78765324999995\&z=4>. Acesso em 02 mai 2018.

BRASIL. Portaria $n^{\circ} 1.707$, de 18 de agosto de 2008. Institui, no âmbito do Sistema Único de Saúde (SUS), o Processo Transexualizador, a ser implantado nas unidades federadas, respeitadas as competências das três esferas de gestão. Diário Oficial da União, Brasília, DF, 2008a.

BRASIL. Portaria $\mathrm{n}^{\circ}$ 457, de 19 de agosto de 2008. Dispõe sobre o Processo Transexualizador no âmbito do Sistema Único de Saúde (SUS). Diário Oficial da União, Brasília, DF, 2008b.

BRASIL. Portaria $n^{\circ} 2.803$, de 19 de novembro de 2013. Redefine e amplia o Processo Transexualizador no Sistema Único de Saúde (SUS). Diário Oficial da União, Brasília, DF, 20 nov. 2013. Seção 1.

BRASIL. Decreto $n^{\circ} 8.727$, de 28 de abril de 2016. Dispõe sobre o uso do nome social e o reconhecimento da identidade de gênero de pessoas travestis e transexuais no âmbito da administração pública federal direta, autárquica e fundacional. Diário Oficial da União, Brasília, DF, 28 abr. 2016.

BUTLER, Judith. Desdiagnosticando o gênero. Physis: Revista de Saúde Coletiva, Rio de Janeiro, v. 19, p. 95-126, 2009.

CASTEL, Pierre-Henri. Algumas reflexões para estabelecer a cronologia do 'fenômeno transexual' (1910-1995). Revista Brasileira de História, São Paulo, v. 21, n. 41, p. 77-111, 2001.

CONSELHO FEDERAL DE MEDICINA. Resolução nº 1.482, de 10 de setembro de 1997. Dispõe sobre a cirurgia de transgenitalismo. Diário Oficial da União, Brasília, DF, p. 20.944, 19 set. 1997.

CONSELHO FEDERAL DE MEDICINA. Resolução n ${ }^{\circ}$ 1.652, de 6 de novembro de 2002. Dispõe sobre a cirurgia de transgenitalismo e revoga a Resolução CFM n ${ }^{\circ}$ 1.482/97. Diário Oficial da União, Brasília, DF, n. 232, p. 80-81, 02 dez. 2002. Seção 1.

CONSELHO FEDERAL DE MEDICINA. Resolução nº 1.955, de 12 de agosto de 2010. Dispõe sobre a cirurgia de transgenitalismo e revoga a Resolução CFM n ${ }^{\circ}$ 1.652/02. Diário Oficial da União, Brasília, DF, p. 109-110, 03 set. 2010. Seção 1.

CONSELHO FEDERAL DE PSICOLOGIA. Nota técnica sobre processo transexualizador e demais formas de assistência às pessoas trans. 4 set. 2013.

CUNHA, Thaís. 2017. Não há vagas...para trans. Correio. Disponível em: $<$ https://bit.ly/2ufPWr1>. Acesso em 02 mai 2018.

CUNHA, Thaís; HANNA, Wellington. 2017. Expulsos da Escola: Discriminação rouba de transexuais o direito ao estudo. Disponível em: <https://bit.ly/2ewRfPg>. Acesso em 02 mai 2018.

FREITAS, Riva Sobrado de; CASTRO, Matheus Felipe de. Liberdade de Expressão e Discurso do Ódio: um exame sobre as possíveis limitações à liberdade de expressão. Sequência, Florianópolis, n. 66, p. 327-355, jul. 2013.

G1. 2017. Brasil é o país que mais mata travestis e transexuais no mundo, diz pesquisa. Disponível em: <https://glo.bo/2ufD9or>. Acesso em 02 mai 2018.

GONÇALVES, Joelma. 2017. 90\% dos transexuais estão fora do mercado formal de trabalho em Sergipe. Disponível em: <https://glo.bo/2OHB79A>. Acesso em 02 mai 2018.

ISTOÉ. 2018. Trans consideram vitória decisão do STF sobre mudança no registro civil. Disponível em: <https://bit.ly/2qJvM84>. Acesso em 20 mai. 2018.

JESUS, Jaqueline Gomes. Orientações Sobre Identidade de Gênero: Conceitos e Termos. E-book. EDA/FBN, Brasília, dez. 2012.

JESUS, Jaqueline Gomes. Transfobia e crimes de ódio: Assassinatos de pessoas transgênero como genocídio. História Agora, v. 16, n. 2, p. 101-123, 2013.

Periódicus, Salvador, n.10, v. 1, nov.2018-abr.2019 - Revista de estudos indisciplinares em gêneros e sexualidades Publicação periódica vinculada ao Grupo de Pesquisa CUS, da Universidade Federal da Bahia - UFBA ISSN: 2358-0844 - Endereço: http://www.portalseer.ufba.br/index.php/revistaperiodicus 
LUCON, Neto. 2017a. Leis que barram discussão sobre gênero nas escolas estão na mira da Procuradoria-Geral da República. Disponível em: <https://bit.ly/2tpumQH>. Acesso em 02 mai 2018.

LUCON, Neto. 2017b. CE, MG, RJ, SP e BA são os piores Estados para ser uma pessoa trans no Brasil. Disponível em: <https://bit.ly/2JXT6b6>. Acesso em 02 mai 2018.

LUCON, Neto. 2017c. Suicídio de militante homem trans em Juiz de Fora abala comunidade. Disponível em: <https://bit.ly/2B1F4CI>. Acesso em 02 mai 2018.

LUCON, Neto. 2017d. Você sabia que o nome social de pessoas trans pode ser incluído no CPF? É simples e gratuito. Disponível em: <https://bit.ly/2T3KuEd>. Acesso em 02 mai 2018.

ONU. 1948. Convenção para a Prevenção e Repressão do Crime de Genocídio. Disponível em: $<$ https://bit.ly/2OEDWIp>. Acesso em: 27 out 2018.

PEREIRA, Luís Filipe. 2017. Proibição de debate sobre gênero em Volta Redonda é inconstitucional, diz TJ-RJ. Disponível em: <https://glo.bo/2Di0hJS>. Acesso em 02 mai 2018.

PORTAL BRASIL. 2016a. Balanço 2016 - Completo: Balanço 2011 a 2016 - LGBT. Disponível em: <https://bit.ly/2JXN1tZ>. Acesso em 02 mai 2018.

PORTAL BRASIL. 2016b. Entenda como vai funcionar o uso do nome social no serviço público: Decreto permite uso em atos e documentos oficiais da administração pública federal. Disponível em: $<$ https://bit.ly/2z4Lgbs>. Acesso em 02 mai 2018.

PORTAL BRASIL. 2017. Disque 100 - Disque Direitos Humanos. Disponível em:<http://www.sdh.gov.br/disque100/disque-direitos-humanos>. Acesso em 02 mai 2018 .

SAADEH, Alexandre. Transtorno de Identidade Sexual: um estudo psicopatológico de transexualismo masculino e feminino. 2004. 266fs. Tese (Doutorado em Ciências) Departamento de Psiquiatria, Universidade de São Paulo, São Paulo, 2004.

TRANSGENDER EUROPE. 2016. Mais de 2,000 pessoas trans assassinadas nos últimos 8 anos: 30 de março de 2016: Nota de Imprensa, Dia Internacional da Visibilidade Trans. Disponível em: $<$ https://bit.ly/2hGYPrQ>. Acesso em 02 mai 2018. 